\title{
A Review on Candidiasis and Opportunistic Mycosis in Human and Animals
}

\author{
Habtamu Tedila* Addisu Assefa Feto Haji \\ College of Natural and Computational Science Department of Biology (Stream of Applied Microbiology), \\ Madda Walabu University, PO box 247, Bale Robe, Ethiopia
}

DOI: $10.7176 / \mathrm{JNSR} / 9-9-01$

Publication date:May $31^{\text {st }} 2019$

\section{INTRODUCTION \\ CANDIDIOSIS}

Candida albicans (C. albicans) is part of the normal microbial flora in human beings and domestic animals, and is associated with the mucous surfaces of the oral cavity, gastrointestinal tract and vagina. Immune dysfunction can allow $C$. albicans to switch from a commensal to a pathogenic organism capable of infecting a variety of tissues and causing a possibly fatal systemic disease (Traynor and Huffnagle, 2001). Mucosal infection is the most usual form of the disease but cutaneous lesions are seen on occasion (Lehmann, 1985).

In cattle, as a consequence of the abundant use, and occasional abuse, of antibiotics in the treatment of mastitis, there is a selection of flora, mainly members of the genus Candida, that are new etiological agents of these processes, which are initially difficult to diagnose because their presence is not expected. Candidiasis in birds is related to malnutrition and stress, generally produced by the same strains that are found naturally on the food plants of these animals. Arthritis caused by yeasts in horses is relatively frequent as a consequence of contamination of wounds or after surgical treatment. In pigs, candidiasis usually takes the form of digestive alterations in young animals, and is usually related to problems that predispose to the disease, like treatment with antibiotics (Garcia and Blanco, 2000). C. albicans is a common causative agent of stomatitis in the dog (Jadhav and Pal, 2006). Although fungi need pre deponent factors to produce the disease, it is known that saprophytic colonization of the mucous membrane by $C$. albicans does not need the host to be immune compromised, since it is detected in immune competent individuals (Garcia and Blanco, 2000).

\section{Etiology}

Candidosis is the most common fungal infection of the oral cavity and is caused by an overgrowth of commensal Candida species. Candida albicans (C. albicans) is the most commonly isolated species in both health and disease. Less common species include C. glabrata, C. tropicalis, C. guilliermondii, C. krusei, C. parapsilosis, and C. kefyr, and more recently, C. dubliniensis (Neville et al., 2002).

\section{Host risk factors}

Endocrine disorders

Diabetes mellitus (DM) may increase susceptibility to development of candidal infections owing to immune system aberrations such as impaired opsonization and decreased chemotactic activity of neutrophils and monocytes (van Burik \&Magee, 2001). Candida-associated lesions including denture stomatitis, median rhomboid glossitis, and angular cheilitis have been reported to be more prevalent in patients with DM (Guggenheimer et al., 2000). The individuals with DM are more prone to candidal infections, particularly when host resistance is modified due to local factors such as smoking and denture wearing (Dorocka-Bobkowska et al., 1996).Patients with poorly controlled DM may exhibit reduced salivary flow rates, reduced salivary $\mathrm{pH}$, increased salivary glucose levels factors known to facilitate oral candida growth and colonization (Bell et al., 1999).

\section{Nutritional factors}

Several nutritional deficiencies may result in a diminished host defense and loss of epithelial integrity, which may facilitate subsequent fungal invasion and infection (Sherman et al., 2002).

Iron deficiency anemia has been proposed as an important factor in the etiology of oral candidosis (Paillaud et al., 2004). Decreased lymphocyte response to Candida antigens in some iron-deficient subjects was associated with an increased frequency of C. albicans in the oral cavity, suggesting that iron deficiency may predispose to oral candidosis by depressing cell-mediated immunity (Sweeney et al., 1994). Deficiencies of vitamin B12 and folic acid may also predispose to oral candidosis (Davenport et al., 2001).

\section{Immune defects, immunosuppression}

Oral candidiasis is a common manifestation in a variety of immune deficiencies. Both humoral and cell-mediated immune systems participate in the prevention and elimination of candidosis (Farah et al., 2010). Reduced or defective immune function increases susceptibility to such infections. In HIV infection, the immunodeficiency affecting T-helper lymphocytes makes the infected patients more predisposed to secondary infections, notably opportunistic candidal infections (Farah et al., 2000). 


\section{High-carbohydrate diet}

High-carbohydrate intake has been assumed to predispose to oral candidosis. This is supported by in vitro studies showing that the growth of Candida in saliva is enhanced by glucose despite the presence of a nutrient competing bacterial salivary flora (Basson, 2000). Furthermore, the adhesive properties of C. albicans to oral epithelial cells and to acrylic surfaces are augmented by dietary carbohydrates. In studies investigating the effects of dietary sugars on candidal adhesion and biofilm formation, glucose was shown to be the most effective followed by galactose and sucrose (Jin et al., 2004).

\section{Pathogenesis}

\section{Virulence factors}

C. albicans has several known virulence factors contributing to its pathogenicity that include adherence to epithelial and endothelial cells, proteinase production (Ross et al., 1990), hypha and pseudohypha formation (Odds et al., 1988), phenotypic switching , phospholipase production (Ibrahim et al., 1995 ), and antigenic modulation as a result of pseudohypha formation (DeBernardis et al., 1994). If C. glabrata is low in virulence, the lack of hypha formation may be a contributing factor. Indeed, hypha formation is a recognized means of increased adherence and tissue invasion by $\mathrm{C}$. albicans as well as a means of increasing proteolytic enzyme elaboration and antigen modulation (Odds, 1988).

Adherence is an extremely important virulence factor, although the actual adherence property may be compounded by other virulence properties. For example, cell surface hydrophobicity (CSH), which is affected by environmental factors, can affect specific adherence based upon interaction of adhesin receptors. In a study with limited numbers of C. glabrata isolates tested, C. glabrata was shown to have comparable CSH to C. albicans (Klotz et al., 1988).

Extracellular membrane-damaging phopholipases are considered virulence factors for C. albicans (Ibrahim et al., 1995). Although these enzymes have not been studied extensively, phospholipase A and B and lysophospholipase-transacylase are produced by virulent but not avirulent (commensal) strains of C. albicans. These phospholipase-producing strains also adhered most strongly to epithelial cells. Furthermore, the production of these phospholipases by clinical isolates correlated with pathogenicity and was predictive of mortality in animal models (Ibrahim et al., 1995). Another virulence factor of C. albicans is specific phenotypic instability, which allows strains to switch colony phenotype without affecting the identifiable genotype; this is termed "phenotypic switching" (Soll, 1988 \& 1992).

\section{Host defenses}

Clinically, this is supported by the fact that neutropenic patients are particularly susceptible to systemic C. albicans infections. In addition, it has been shown in an animal model that $\mathrm{T}$ cells may be of some significance against systemic $C$. albicans infections. Specifically, studies in mice have shown that a Th1-type response characterized by the cytokines interleukin-2 (IL-2), gamma interferon, and IL-12 is associated with protection against systemic infection whereas Th2-type responses characterized by the cytokines IL-4, IL-5, and IL-10 and antibody production (immunoglobulin $\mathrm{A}[\mathrm{IgA}]$ and $\operatorname{IgE}$ ) is associated with susceptibility to systemic infection (Romani et al., 1996). T cells and cell-mediated immunity (CMI), on the other hand, form the predominant host defense mechanism against mucosal C. albicans infection. This comes from both clinical observations (a high incidence of mucosal candidiasis in patients with reduced CMI) and clinical and experimental studies showing the critical role of $\mathrm{T}$ cells in protection against $C$. albicans mucosal infections (i.e., chronic mucocutaneous candidiasis and gastrointestinal candidiasis) (Bennett,1990).

\section{Preventive measures}

Any nutritional deficiency states (iron, folate and vitamin B12), diabetes mellitus, and any immune deficiencies should be excluded (Farah et al., 2010; Williams et al., 2011; McCollough \& Salvage, 2005). Any pharmacologic agents that may contribute should be identified, and if practical, substituted for an alternative drug. Use of corticosteroid inhalers for asthma should be coupled with rinsing the mouth with water after each use (Williams et al., 2011).

\section{ASPERGILLOSIS}

Aspergillosis is the group of diseases caused by Aspergillus. The most common subtype among paranasal sinus infections associated with aspergillosis is Aspergillus fumigatus (A. fumigatus). In humans, the major forms of disease are; Allergic bronchus pulmonary aspergillosis, which affects patients with respiratory diseases such as asthma, cystic fibrosis, and sinusitis, Acute invasive aspergillosis, a form that grows into surrounding tissue, more common in those with weakened immune systems such as AIDS or chemotherapy patients, Disseminated invasive aspergillosis, an infection spread widely through the body, Aspergilloma, a "fungus ball" that can form within cavities such as the lung (Bozkurt et al., 2008).

In humans, the lungs are the most common location of Aspergillus infections but in domestic animals, the situation is different and varies between species. For example, in cows, the fore stomachs, especially the omasum, are mostly affected, from which the infection may spread to other organs, including the placenta (Garcia et al., 
2001a). A few cases of pulmonary involvement and later dissemination have been reported in dogs (Clercx et al., 1996). Aspergillosis of the air passages is also frequently reported in birds, and certain species of Aspergillus have been known to infect insects (Geiser, 2009).

\section{Etiology}

Aspergillus was first described in 1729 and receives its name due to its resemblance to an aspergillum used to sprinkle holy water. A member of the family Trichocomaceae, Aspergillus species are closely related to another mold, Penicillium. However, identification of the causative organism responsible for most infections is usually not difficult, with four species responsible for the majority of illnesses. A. fumigatus is responsible for more than $90 \%$ of invasive disease in some reviews, with Aspergillus flavus (A. flavus), Aspergillus terreus (A. terreus), and Aspergillus niger (A. niger) responsible for the majority of remaining invasive aspergillosis cases (Patterson et al., 2000).

\section{Host risk factors}

Risk factors for invasive aspergillosis may be associated with the changes in macrophage and neutrophil function, which may explain why infection mainly affects bone marrow and solid organ transplant recipients, Intensive Care Unit (ICU) patients, post-operative patients, those with chronic pulmonary diseases, patients with AIDS and patients on immune modulating drugs (TNF- $\alpha$ inhibitors), neutropenic patients, or those who have received corticosteroid treatment. Other risk group is patients with chronic granulomatous disease, drug user, patients with sarcoidosis, severe burn patients and alcoholics (Ascioglu et al., 2002). Aspergillus can also develop when no risk factors are present. Thus, cases have been explained of community-acquired pneumonia due to Aspergillus in apparently immune competent patients (Franquet et al., 2001) but it is likely that the patients had some undetected defect in macrophage and neutrophil function that allowed invasive infection to develop.

Malnutrition, vitamin deficiencies (especially vitamin A), long term antibiotic use, age (young or old) also contributes to the presentation of the disease, as well as trauma, dusty environments, lead poisoning and irritants of the airways like smoke of cigarette or ammonia (Washburn et al., 1990).

\section{Pathogenesis}

\section{Virulence factors}

Aspergilli produce catalase, an enzyme that breaks down hydrogen peroxide $(\mathrm{H} 2 \mathrm{O} 2)$ to water and oxygen. The strong association of aspergillosis with chronic granulomatous disease (CGD) (Cohen et al., 1981) provides indirect evidence that catalase is a virulence factor. A. fumigatus produces gliotoxin, a metabolite in the epipolythiodioxopiperazine family with a broad range of immunosuppressive properties. Gliotoxin inhibits macrophage phagocytosis (Eichner et al., 1986), as well as T-cell activation and proliferation. It induces DNA fragmentation and programmed cell death (apoptosis) in macrophages by mechanisms apparently distinct from its antiphagocytic properties (Waring, 1990). It is not known whether clinically significant amounts of gliotoxin are produced in human disease. In a case report, concentrations of gliotoxin approximately 100 times greater than that needed for in vitro effects were found in a bovine udder infected with A.fumigatus (Bauer et al., 1989).

In addition to gliotoxin, A. fumigatus produces an $18-\mathrm{kDa}$ cytotoxin that acts by cleaving a phosphodiester bond of the 28S rRNA of eukaryotic ribosomes (Smith et al., 1993).

\section{Host defense}

Antigen release evokes production of $\operatorname{IgE}, \operatorname{IgG}$ and $\operatorname{IgA}$ antibody against the A.fumigatus and intense production of nonspecific total IgE. IgE mediated mast cell degranulation in the bronchi release mediators that would cause bronchospasm as well as permeability changes in the epithelium. Eosinophilic chemotactic factors cause pulmonary and peripheral blood eosinophilia IgG-A.fumigatus, IgA-A.fumigatus also causes activation of complement in the bronchi. It has been demonstrated that there occurs hyper releasability of histamme from basophils of ABPA patients (Ricketti et al., 1983).

\section{Preventive Measures}

In developed countries, where regulations allow higher aflatoxin concentrations in animals, the agricultural industries have developed alternative approaches chemoprotection and enterosorption to limit biologically effective exposure without the high cost of preventing contamination. Chemoprotection is based on manipulating the biochemical processing of aflatoxin to ensure detoxification rather than preventing biological exposure. Enterosorption is based on the approach of adding a binding agent to food to prevent the absorption of the toxin while the food is in the digestive tract; the combined toxin-sorbent is then excreted in the feces. This approach has been used extensively and with great success in the animal feeding industry. (Williams et al., 2004).

It has been shown that HEPA filtration can reduce or even eliminate Aspergillus spores from the air (Comet et al., 1999). Caring for high-risk patients in rooms supplied with HEPA-filtered air has helped to prevent the acquisition of this infection within the hospital (Oren et al., 2001), provided certain technical requirements are met. Components of a protected hospital environment should include a well-sealed room, HEPA filtration of incoming air, directed (or laminar) airflow within the room, positive room air pressure relative to the corridor, and high rates of room air exchange (Center for Disease Control and Prevention, 1997) 


\section{CRYPTOCOCCOSIS}

Cryptococcosis is a rare fungal infection produced by inhalation of encapsulated yeast called Cryptococcus neoformans. C. neoformans can be found worldwide in soil, pigeon/bird, cat, dog, fox, monkey, cattle, horse, goat, and many other mammals' feces (www.doctorfungus.org, 2008). Recently, a differentiation has been made between two species, Cryptococcus gattii (C.gattii) and C. neoformans. This differentiation was made on the basis of genetic variation and a lack of evidence for genetic recombination between both gene types (Duncan et al., 2006a, b). These genetic differences are consistent with differences in habitat, geographical distribution and, most importantly, in pathogenicity and the effectiveness of the response of the host immune system. C.neoformans infects predominantly immune compromised hosts, while $C$. gattii has not been associated with a suppressed immune system (Duncan et al.,2006a,b) and is mostly found on eucalyptus trees and in the soil (Traynor and Huffnagle, 2001; Duncan et al.,2006a).

The primary route of entry for Cryptococcus is via the lungs, where the fungus may establish a primary infection. If the initial pulmonary infection is not controlled, the fungus can disseminate to other organs and the central nervous system, resulting in fatal cryptococcal meningoencephalitis (Traynor and Huffnagle, 2001; Aguirre et al., 2004; Chen et al., 2007).

Human disseminated cryptococcosis has two unusual features that distinguish it from other disseminated fungal infections. First, patients have cryptococcal polysaccharide antigen in their body fluids, and detection of this is useful in diagnosis of the disease. Second, there is a limited inflammatory response in tissues harbouring $C$. neoformans. One could interpret these findings to mean that individuals with the highest levels of cryptococcal polysaccharide in their body fluids simply had higher number of organisms in their tissues and therefore were the most likely not to respond to antifungal therapy. Another interpretation could be that the cryptococcal polysaccharide had an adverse effect on host defence mechanisms, thus allowing a progressive disease, concluding that cryptococcal polysaccharide in the bloodstream exacerbates disease (Clemons et al., 2000).

Clinical cryptococcosis has been reported worldwide in many animal species. It is the most common systemic fungal infection in cats and is often described in dogs (Duncan et al., 2006b). In cats, C. neoformans is most commonly isolated from immunosuppressed individuals, whereas $C$. gattii is considered as primary pathogen because it infects immune competent hosts, even in areas where the organism is endemic (Duncan et al., 2006a). In other animal species, cryptococcosis can appear to be related to immune depression, although not always. Then, have been described outbreaks of ovine and caprine cryptococcosis with respiratory signs, and without immune depression situation detected in those animals (Garcia and Blanco, 2000). In these cases, respiratory symptoms associated with cachexia were the predominant clinical picture; liver and brain involvement was also documented (Baro et al., 1998).

Cryptococcosis may occur in horses as a disseminated cryptococcal infection with osteomylitis of both the axial and appendicular skeleton produced by C.gattii. The administration of corticoids led to clinical deterioration due to immune modulating effects. Administration of systemic corticoids occurred after lesions had appeared; however, the horse deteriorated significantly after corticosteroid treatment (Lenard et al., 2007).

Etiology

Cryptococcus spps. are fungi in the Division Basidiomycota. Although there are more than 30 species of Cryptococcus, only two organisms - C. neoformans and C. gattii (previously C. neoformans var. gattii) commonly affect humans and animals. Other species including C. laurentii, C. albidus, C. uzbekistanensis, $C$. adeliensis, C. curvatus, C. magnus, C. humicolus, C. luteolus, C. macerans, C. flavescens and C. uniguttulatus have been found in clinical cases; however, this is rare. Of the latter group of organisms, C. laurentii and C. albidus have been described most often in people (The Center for Food Security and Public Health, 2013).

\section{Host risk factors}

C. neoformansis also an opportunistic pathogen, which can cause cryptococcosis in patients with

HIV infection and HIV-negative patients with immunological conditions predisposing to this fungal infection, such as a history of systemic corticosteroid therapy, immunosuppressive treatments, organ transplant, chronic organ failure (liver, lung, and kidney), malignancy, rheumatic diseases, systemic lupus erythematosus and diabetes mellitus (Casadevall et al., 2008).

\section{Pathogenesis}

\section{Virulence Factors}

C. gattii and C. neoformans share many attributes that increase their ability to invade and survive in a host organism (Ellerbroek et al., 2004). The main virulence factors identified in C. gattii to date include an outer polysaccharide capsule, melanin, mannitol, extracellular proteinase, products of the laccase pathway, superoxide dismutase, phospholipases, urease, and the STE12 transcription factor (a homologue of Saccharomyces cerevisiae STE12) that is present only in the mating type(Chang et al., 2000). Other properties of C. gattii contribute to its infectivity such as its ability to grow at physiological temperature (Sorrel, 2001) its tolerance of low pH and elevated salt levels (Kidd et al., 2007), and its ability to switch capsular phenotype (Jian et al., 2006). 


\section{Host defenses}

Clearance of Cryptococcus infection requires the development of a Th1-type CMI and the subsequent pulmonary recruitment and activation of leukocytes. The leukocytic infiltrate in response to cryptococcal infection includes a mix of myeloid and lymphoid cells, all of which are capable of inhibiting the growth of, or killing, the organism in vitro (Romani, 2004).

Neutrophils and macrophages are the two phagocytic cells in the natural host defence that are most likely to be responsible for clearing the cryptococcal cells from the tissues. There was very little inflammatory response, i.e. influx of neutrophils, lymphocytes and macrophages, into infected host tissues (Clemons et al., 2000).

In this Th1-CMI, IFN-g, TNF-a, IL-2, IL-12, IL-15, IL-18, monocyte chemotactic protein-1, macrophage inflammatory protein-1a and nitric oxide have been shown to have important roles in murine models. GM-CSF plays a complex role in the development of anticryptococcal immunity in the lungs: it is required for early recruitment of leukocytes into the lung, movement of recruited leukocytes into the alveolar space and the formation of inflammatory foci in the lungs (Chen et al., 2007).

The Th2 cytokines IL-4 and IL-5 were not secreted at significantly higher levels in Cryptococcus-infected brains of immune mice compared to control mice (Uicker et al., 2005). CD4+ T-cells are critical for the control of Cryptococcus. An antigen-specific CD4+ T cell response occurs when the T cell receptor recognizes processed antigen fragments presented by MHC Class II. Then CD4+ T cells secrete cytokines and proliferate (Kwon-Chung et al., 2000). Nevertheless, in the lung, both CD4+ andCD8+ T cells are required to clear the cryptococcal infection. If yeasts escape and colonize the brain, rapid proliferation leads to serious central nervous system disease. Work with severe T cell and B cell-deficient combined immune deficient mice and wild-type controls has demonstrated a CD4+ T cell-mediated resistance to cryptococcal organisms that colonize the brain. Depletion of CD8+ T cells had no detectable effect on T cell-mediated resistance in brain in vivo. In contrast, CD8+ T cells play a welldefined and important role in containment of pulmonary infection (Aguirre et al., 2004).

\section{Preventive measures}

There is no vaccine available for cryptococcosis; thus, prevention through environmental condition control is vital. Reduction of aerosolization of the $C$. neoformans is key and should be done wetting or chemically disinfecting a region, then removing large accumulations of bird/animal droppings. Corticosteroid medications usage should be minimized to prevent cryptococcosis due to their tendency of exacerbating compromised patients conditions (http://www.aidsmap.com/en/news; McCarthy, 2006).

\section{FUSARIOSIS}

Fusarium spp.are important infectious filamentous fungi, second only to Aspergillus spp. These fungi are ubiquitous in the environment and are found in the soil and air. Interestingly, Fusarium spp. are primarily known as plant pathogens but can also infect humans and animals, causing superficial, locally invasive, and disseminated disease.(Nucci and Anaissie, 2007). Infection is mainly through inhalation of airborne conidia or via breaks in the skin due to trauma and/or burns. Fusarium spp. also produces toxins that can cause food poisoning through the consumption of toxin-contaminated food (Dignani \& Anaissie, 2004).

In humans, Fusarium species cause a broad spectrum of infections, including superficial (such as keratitis and onychomycosis), locally invasive, or disseminated infections, with the last occurring almost exclusively in severely immunocompromised patients (Nucci \& Anaissie, 2002). Fusarium species may also cause allergic diseases (sinusitis) in immunocompetent individuals (Wickern, 1993) and mycotoxicosis in humans and animals following ingestion of food contaminated by toxin-producing Fusarium spp. (Nelson et al., 1994)

\section{Etiology}

More than 100 species of Fusarium have been identified, but only a few cause infections in humans (Alastruey et al., 2008). Fusarium solani (F.solani) is the most frequent cause of invasive disease (in approximately half of all cases), followed by $F$. oxysporum, $F$. moniliforme (previously $F$. verticillioides), and $F$. proliferatum (Torres et al., 2011). Other species that rarely cause infections in humans include F. dimerum, F. chlamidosporum, $F$. sacchari, F. antophilum and others. Fusarial keratitis is most commonly caused by F. solani (Doczi et al., 2004), whereas fusarial onychomycosis is most commonly caused by F. oxysporum(Brilhante et al., 2005; Godoy et al., 2004; Ninet et al., 2005).

\section{Host risk factors}

Neutropenia is one of the most important risk factors for acquiring fusariosis. Patients undergoing Heamtopoetic Stem Cell Transplantation(HSCT) or solid organ transplantation, those with hematological malignancies or acquired immune deficiency syndrome (AIDS) and those taking pharmacological immunosuppressant therapies are at high risk for fusariosis.(Nucci et al., 2004 \& Enoch et al., 2006).

\section{Pathogenesis}

\section{Virulence Factors}

Fusarium species possess several virulence factors, including the ability to produce mycotoxins, including trichothecenes, which suppress hum oral and cellular immunity and may also cause tissue breakdown. In addition, 
Fusarium species have the ability to adhere to prosthetic material and to produce proteases and collagenases (Nelson, 1994).

\section{Host Defenses}

The innate immunity plays a major role in the defense against mold infections (Shoham\& Levitz, 2005). Macrophages and neutrophils damage fusarial hyphae, and their effect is primed by gamma interferon, granulocyte colony-stimulating factor (G-CSF), granulocyte-macrophage colony-stimulating factor (GM-CSF) (Gaviria et al., 1999), and interleukin-15 (Winn et al., 2005). The importance of T-cell defenses against Fusarium is illustrated by the occurrence of disseminated fusariosis in non-neutropenic HSCT recipients (Nucci et al., 2004). These patients have severe T-cell immunodeficiency caused by multiple therapies for their underlying disease and for graft-versus-host disease (GvHD). Further supporting the importance of T-cell immunity and phagocytes is the major impact of corticosteroid therapy on the outcome of fusariosis, as shown by the much higher death rate among recipients of such therapy than among patients who were not receiving corticosteroids (Nucci et al., 2003).

\section{Preventive measures}

General preventive measures that should be employed in patients at significant risk of invasive fusariosis, such as patients with hematologic malignancies undergoing induction chemotherapy or hematopoietic cell transplantation, include: Avoidance of activities associated with skin breakdown, avoidance of contact of areas of skin breakdown with tap water., Careful examination for and treatment of onychomycosis and paronychia and surgical debridement of infected wounds prior to commencing anti-cancer therapies, delaying severely immunosuppressive therapies until areas of skin breakdown are healed, when possible. (Nucci \& Anaissie, 2007; Nucci \& Anaissie, 2002).

Following appropriate air and water precautions during periods at risk. These include use of a high efficiency particulate air filter and positive pressure isolation rooms, avoiding contact with reservoirs of Fusarium spp, such as tap water, and having showers cleaned thoroughly prior to use by high-risk patients(Anaissie et al.,2001; Anaissie et al., 2002 ).

\section{PNEUMOCYTIS}

Pneumocystis carinii (P.carinii) is an opportunistic and widespread fungus found in the lungs of humans and other mammals. It can be the cause of severe pneumonia, especially in humans suffering from AIDS (Cailliez et al., 1991). In the veterinary literature $P$. carinii pneumonia (PCP) has been reported in foals 1 ,(Tanaka et al., 1994) (especially Arabian foals with inherited severe combined immunodeficiency, in pigs,(Kondo et al., 1993) and in domestic goats. Only a few cases of $P$. carinii pneumonia have been reported in dogs, and most commonly among young animals (Furuta et al., 1994). P. carinii was considered as a group of heterogeneous populations, genetically isolated from each other, that have undergone a prolonged process of genetic and functional adaptation to each mammalian species (Dei-Cas, 2000).

Further genetic analysis has shown that Pneumocystis isolated from different species has significant differences in gene sequence and chromosomes. This has prompted nomenclature changes and $P$. carinii is now reserved for the rat pathogen, P.carinii f.sp. muris for the murine pathogen, and P. jiroveci for the human pathogen (Steele et al., 2005). It may be that this situation will be repeated in different animal species, like the description of the genetically different $P$. canis in dog (English et al., 2001). Pneumocystis pneumonia is a well-recognized major opportunistic infection in HIV-positive individuals, and is growing in importance in HIV-negative patients undergoing immunosuppressive treatment for malignancy, connective tissue disease or organ transplantation.

In the veterinary field, Pneumocystis has been described as producing pneumonia in dogs, causing serious pulmonary alterations. Pneumocystis is important in horses, where treatment with immunosuppressive drugs, like corticoids, is a relatively frequent practice in animals.

Dedicated to sport, originating a pneumonic process with bronchoneumonic diffuse image. In pigs, this fungus gives rise to pneumonic processes, affecting animals 7-11 weeks old, with lung damage that includes a decrease of the size of the pulmonary septa with infiltration of mononuclear cells and appearance of exudates in the alveoli. This focal pneumonia evolves toward a diffuse pneumonia, very similar to what happens with this disease in children (Cavallini et al., 2007). Pneumocystis infects hosts by a respiratory route, and animal-to-animal airborne transmission has been clearly established (Dumoulin et al., 2000). In humans, the persistence of Pneumocystis in the lung is a limited-time phenomenon inversely related to immunological improvement. A normal immune response completely eradicates Pneumocystis from the host. However, immunocompetent hosts can be parasitized transiently by Pneumocystis: increased titres of Pneumocystis antibodies were detected in hospital staff in close contact with Pneumocystis pneumonia patients, and immunocompetent experimental hosts were parasitized transiently by Pneumocystis after close contact with hosts developing pneumonia by this fungus (Dei-Cas, 2000).

\section{Etiology}

Pneumocystis organisms were first reported and named P.carinii in the beginning of last century after recognition that pneumocystis organisms in different mammals are different, in1994 an interim trinomial name change was adopted with the name $P$. carinii f.sp hominis for pneumocystis infecting humans and P.carinii f.sp. carinii for 
one of the two species infecting rats (The Pneumocystis Workshop, 1994). Finally, in 2002, by the recognition of its genetic and functional distinctness, human pneumocystis organism was renamed Pneumocystis jiroveci, in honour of Otto Jirovec, who is credited for describing the microbe in humans (Frenkel, 1999; Stringer et al., 2002). Host risk factors

Although not fully characterized, the known risk factors for P.jirovecii infection include impaired immunity because of HIV infection, hematologic malignancies, and connective tissue disorders (Roblot et al., 2002).

\section{Pathogenesis}

Host defense

A host defense against Pneumocystis is indistinguishable from that observed for other medically important fungal pathogens of the lung (Steele et al., 2005). As with fungal pathogens such as A. fumigatus, C.neoformans and Histoplasma capsulatum( $H$. capsulatum), alveolar macrophages are an essential component of the immune response against Pneumocystis and are ultimately responsible for clearing this fungus from the lungs ( $\mathrm{He}$ et al.,2003; Steele et al., 2005). CD4+ T cells are absolutely critical for resolution of Pneumocystis, having an essential role in the recruitment and activation of effector cells against the organism. CD8+ T cells by themselves do not aid clearance of Pneumocystis from the lungs (Dei-Cas, 2000; Traynor \& Huffnagle, 2001)

$\mathrm{IFN}^{-} \gamma$ is not absolutely required for clearing Pneumocystis from the lungs but is required for modulating the inflammation (Dei-Cas, 2000). B cells and/or Pneumocystis-specific antibody are important for clearance of Pneumocystis from the lungs. Antibodies against Pneumocystis are reported to be readily detectable in the early years of life, at ages similar to that reported for other pathogenic fungi such as C. albicans and C. neoformans (Goldman et al., 2001; Steele et al., 2005), and most data suggest that the organism is widely encountered in nature and that antibody production is part of the natural host response, predominantly of the IgG class, but also IgM. In this sense, many ELISA-based assays have been developed and employ a wide variety of Pneumocystis preparations and antigens to detect the presence of Pneumocystis-specific antibodies (Steele et al., 2005).

\section{Preventive Measures}

Adults and adolescents who have HIV infection (including pregnant women and those on HAART) should receive Chemoprophylaxis against PCP if they have a CD4+ T-lymphocyte count of less than 200/ $\mu \mathrm{L}$ or a history of or pharyngeal candidiasis (Phair et al., 1990). Persons who have a CD4+ T-lymphocyte percentage of less than 14\% or history of an acquired immunodeficiency syndrome (AIDS)-defining illness but do not otherwise qualify should be considered or prophylaxis (Kaplan et al., 1998). When monitoring the CD4+ T-lymphocyte count at least every 3 months is not possible, initiation of chemoprophylaxis at a CD4+ T-lymphocyte count of greater than 200 but less than 250 cells/ $\mu \mathrm{L}$ also should be considered (CDC, 1989).

\section{Competing Interests}

The authors declare that they have no competing interests.

\section{Acknowledgments}

The authors are thankful to library and ICT office of Madda Walabu University for providing the facilities to prepare this review paper.

\section{REFERENCE}

Aguirre, K., Crowe, J., Haas, A. and Smith, J. (2004): Resistance to Cryptococcus neoformans infection in the absence of CD4+ T cells. Med. Mycol., 42:15-25.

Alastruey-Izquierdo A, Cuenca-Estrella M, Monzón A, et al (2008): Antifungal susceptibility profile of clinical Fusarium spp. isolates identified by molecular methods. J Antimicrob Chemother; 61:805.

Anaissie EJ, Kuchar RT, Rex JH, et al (2001): Fusariosis associated with pathogenic fusarium species colonization of a hospital water system: a new paradigm for the epidemiology of opportunistic mold infections. Clin Infect Dis; 33:1871.

Anaissie EJ, Stratton SL, Dignani MC, et al (2002): Cleaning patient shower facilities: a novel approach to reducing patient exposure to aerosolized Aspergillus species and other opportunistic molds. Clin Infect Dis 35:E86.

ANON

Cryptococcosis.

2008.

Available from:http://www.doctorfungus.org/mycoses/human/crypto/Crypto_index.htm Accessed date: 2008 March 3.

Ascioglu S, Rex JH, de Pauw B, Bennett JE, \& Bille J, et al. (2002): Defining opportunistic invasive fungal infections in immunocompromised patients with cancer and hematopoietic stem cell transplants: An international consensus. Clin Infect Dis 34: 7-14.

Baro, T., Torres-Rodriguez, J.M., Hermoso de Mendoza, M., Morera, Y., Alia, C., (1998): First identification of autochtonous Cryptococcus neoformonans var. gattii isolated from goats with predominantly severe pulmonary disease in Spain. J. Clin. Microbiol.36, 458-461.

Basson NJ (2000): Competition for glucose between Candida albicans and oral bacteria grown in mixed culture in 
a chemostat. J Med Microbiol. 49: 969-975.

Bauer,J.,Gareis.M,Bott.A,andGedek.B.(1989):Isolationofamycotoxin(gliotoxin) fromabovineudderinfectedwith Aspergillusfumigatus.J.Med.Vet. Mycol.27:45-50.

Bell GW, Large DM, Barclay SC. (1999): Oral health in diabetes mellitus. Dent Annu Rev Microbiol.; 55: 743 772.

Bennett J. E. (1990): Antimicrobial agents: antifungal agents. in Goodman and Gilman's the pharmacological basis of therapeutics. eds Gilman A. G., Rall T. W., Nies A. S., Taylor P. (Pergamon Press, Inc. Elmsford, N.Y), pp 1165-1181.

Bozkurt MK, Ozcelik T, Saydam L, Kutluay L (2008): A case of isolated aspergillosis of the maxillary sinus. Kulak Burun Bogaz Ihtis Derg.; 18(1): 53-5.

Brilhante RS, Cordeiro RA, Medrano DJ, et al (2005): Onychomycosis in Ceará (Northeast Brazil): epidemiological and laboratory aspects. Mem Inst Oswaldo Cruz; 100:131.

Cailliez, J. C., Se'guy.N, Denis.C.M, Aliouat E.M, Mazars.E, Polonelly.L, Camus.D, and Dei-Cas E,(1996): Pneumocystis carinii: an atypical fungal microorganism. J. Med. Vet. Mycol. 34:227-239.

Casadevall A. Cryptococcosis. In: Fauci AS, Braunwald E, Kasper DL, et al (2008):. Harrison's principles of internal medicine. $17^{\text {th }} e d$. New York: McGraw-Hill Medical Publishing Division; pp. 1251-3.

Cavallini, E.M., Pescador, C., Rozza, D., Spanamberg, A., Borba M.R., Ravazzolo, A.P., Driemeier, D., Guillot, J., Ferreiro, L., (2007): Detection of Penumocystis spp. in lung samples from pigs in Brazil. Med. Mycol. 45, 395-399.

CDC (1989): Guidelines for prophylaxis against Pneumocystis carinii pneumonia for persons infected with human immunodeficiency virus. $M M W R ; 38(\operatorname{suppl} 5): 1-9$.

Centers for Disease Control and Prevention (1997): Guidelines for prevention of nosocomial pneumonia. $M M W R$, 46: RR-01.

Chang Y.C., B. L. Wickes, G. F. Miller, L. A. Penoyer, and K. J. Kwon-Chung (2000): “Cryptococcus neoformans STE12 $\alpha$ regulates virulence but is not essential for mating," Journal of Experimental Medicine, vol. 191, no. 5 , pp. 871-882.

Chen, G.H., Olszewski, M.A., McDonald, R.A., Wells, J.C., Paine III, R., Huffnagle, G.B., Toews, G.B., 2007. Role of granulocyte macrophage colony-stimulating factor in host defense against pulmonary Cryptococcus neoformans infection during murine allergic bronchopulmonary mycosis. Am. J. Pathol. 170, 1028-1040.

Clemons, K.V., Calich, V.L.G., Burger, E., Filler, S.G., Graziutti, M.,Murphy, J., Roilides, E., Campa, A., Dias, M.R., Edwards, J.E., Fu, Y., Fernandes-Bordignon, G., Ibrahim, A., Katsifa, H.,Lamaignere, C.G., MeloniBruneri, L.H., Rex, J., Savary, C.A.,Xidieh, C., 2000.Pathogenesis I: interactions of host cells and fungi. Med. Mycol. 38 (Suppl. 1), 99-111.

Clercx, C., McEntee, K., Snaps, F., Jacquinet, E., Coignoul, F., (1996): Bronchopulmonary and disseminated granulomatous disease associated with Aspergillus fumigatus and Candida species infection in a Golden Retriever. J. Am. Anim. Hosp. Assoc. 32, 139-145.

Cohen, M. S., R. E. Isturiz, H. L. Malech, R. K. Root, C. M. Wilfert, L. Gutman, and R. H. Buckley(1981): Fungal infection in chronic granulomatous disease. The importance of the phagocyte in defense against fungi. Am. J. Med.71:59-66.

Cornet M, Levy V, Fleury L, et al (1999): Efficacy of prevention by high-efficiency particulate air filtration or laminar airflow against aspergillus airborne contamination during hospital renovation. Infect Control Hosp Epidemiol ; 20:508-513.

Davenport JC, Basker RM, Heath JR, Ralph JP, Glantz PO, Hammond P (2001): Initial prosthetic treatment. $\mathrm{Br}$ Dent J.190: 235-244.

DeBernardis F., Molinari A., Boccanera M., Stringaro A., Robert R., Senet J. M., Arancia G., Cassone A.(1994):Modulation of cell surface-associated mannoprotein antigen expression in experimental candidal vaginitis. Infect. Immun. 62:509-519.

Dei-Cas, E., (2000): Pneumocystis infections: the iceberg? Med.Mycol. 38 (Suppl. 1), 23-32.

Dignani MC, Anaissie E(2004) : Human fusariosis. Clin Microbiol Infect; 10 Suppl 1:67-75

Dóczi I, Gyetvai T, Kredics L, Nagy E (2004): Involvement of Fusarium spp. in fungal keratitis. Clin Microbiol Infect; 10:773.

Dorocka-Bobkowska B, Budtz-Jorgensen E, Wloch S (1996): Non-insulin dependent diabetes mellitus as a risk factor for denture stomatitis. J Oral Pathol Med.25: 411-415.

Dumoulin, A., Mazars, E., Seguy, N., Gargallo-Viola, D., Vargas, S., Cailliez, J.C., Aliouat, E.M., Wakefield, A.E., Dei-Cas, E.,( 2000) : Transmission of Pneumocystis carinii disease from immunocompetent contacts of infected hosts to susceptible hosts. Eur. J. Clin.

Duncan, C.G., Stephen, C., Campbell, J., (2006a): Evaluation of risk factors for Cryptococcus gattii infection in dogs and cats. J. Am.Vet. Med. Assoc. 228, 377-382.

Duncan, C.G., Stephen, C., Campbell, J.,( 2006b): Clinical characteristics and predictors of mortality for 
Cryptococcus gattii infection in dogs and cats of southwestern British Columbia. Can. Vet. J. 47,993-998.

Eichner, R. D., M. Al Salami, P. R. Wood, and A. Mullbacher (1986): The effect of gliotoxin upon macrophage function. Int. J. Immunopharmacol.8:789-797.

Ellerbroek P.M., Walenkamp A.M.E, Hoepelman A.I.M, and Coenjaerts F.E.J. (2004): "Effects of the capsular polysaccharides of Cryptococcus neoformans on phagocyte migration and inflammatory mediators," Current Medicinal Chemistry, vol. 11, no. 2, pp. 253-266.

English, K., Peters, S.E., Meskell, D.J., Collins, M.E., (2001): DNAanalysis of Pneumocystis infecting a Cavalier King Charles Spaniel.J. Eukaryot. Microbiol. Suppl. 106S.

Enoch DA, Ludlam HA, Brown NM. Invasive fungal infections (2006): a review of epidemiology and management options. J Med Microbiol; 55:809-18.

Farah CS, Ashman RB, Challacombe SJ (2000): Oral candidosis. Clin Dermatol; 18: 553-562.

Farah CS, Lynch N, McCullough MJ (2010): Oral fungal infections: An update for the general practitioner. Aust Dent J.; 55 (Suppl 1): 48-54.

Franquet T, Müller NL, Giménez A, Guembe P, de La Torre J, et al. (2001): Spectrum of pulmonary aspergillosis: histologic, clinical, and radiologic findings. Radiographics 21: 825-837.

Frenkel JK (1999): Pneumocystis pneumonia, an immunodeficiency-dependent disease (IDD): a critical historical overview. J Eukaryot Microbiol 46(5):89S-92S.

Furuta T, Nogami S, Kojima S, et al., (1994): Spontaneous Pneumocystis carinii infection in the dog with naturally acquired generalised demodicosis. Vet Rec 134:423-424.

Garcia, M.E., Blanco, J.L., (2000): Principales enfermedades fu'ngicasque afectan a los animales dome'sticos. Rev. Iberoam. Micol. 17, S2-S7.

Garcia, M.E., Blanco, J.L., (2000): Principales enfermedades fu'ngicasque afectan a los animales dome'sticos. Rev. Iberoam. Micol. 17, S2-S7.

Garcia, M.E., Caro, A., Fragio, C., Blanco, I., Blanco, J.L., (2001a): A clinical case of canine mycotic pneumonia. J. Vet. Med. A; 48,501-506.

Gaviria, J. M., J. A. van Burik, D. C. Dale, R. K. Root, and W. C. Liles.(1999) : Comparison of interferon-gamma, granulocyte colony-stimulating factor, and granulocyte-macrophage colony-stimulating factor for priming leukocyte-mediated hyphal damage of opportunistic fungal pathogens.J. Infect. Dis. 179:1038-1041.

Geiser, D. (2009): "Sexual structures in Aspergillus: morphology, importance and genomics". Medical mycology: official publication of the International Society for Human and Animal Mycology. 47. Suppl 1 (s1): S21-S26.

Godoy P, Nunes E, Silva V, et al (2004). Onychomycosis caused by Fusarium solani and Fusarium oxysporum in São Paulo, Brazil. Mycopathologia; 157:287.

Goldman, D.L., Khine, H., Abadi, J., Lindenberg, D.J., Pirofski, L., Niang, R., Casadevall, A., (2001): Serologic evidence for Cryptococcus neoformans infection in early childhood. Pediatrics 107, E66.

Guggenheimer J, Moore PA, Rossie K, Myers D, Mongelluzzo MB, Block HM, Weyant R, Orchard T; (2000) : Insulin-dependent diabetes mellitus and oral soft tissue pathologies: II. Prevalence and characteristics of candida and candidal lesions. Oral Surg Oral Med Oral Pathol Oral Radiol Endod. 89: 570-576.

He, W., Casadevall, A., Lee, S.C., Goldman, D.L., (2003): Phagocytic activity and monocyte chemotactic protein expression by pulmonary macrophages in persistent pulmonary cryptococosis. Infect.Immun. 71, 930-936.

Ibrahim A. S., Mirbod F., Filler S. G., Yoshiko B., Cole G., Kitajima Y., Edwards J. E. Jr., Nosawa Y., Ghannoum M. A. (1995): Evidence implicating phospholipase as a virulence factor of Candida albicans. Infect. Immun. 63:1993-1998.

Jadhav, V.J., Pal, M., (2006): Canine mycotic stomatitis due to Candida albicans. Rev. Iberoam. Micol. 23, 233 234.

Jin Y, Samaranayake LP, Samaranayake Y, Yip HK (2004): Biofilm formation of Candida albicans is variably affected by saliva and dietary sugars. Arch Oral Biol.; 49: 789-798.

Kaplan JE, Hanson DL, Navin TR, Jones JL (1998): Risk factors for primary Pneumocystis carinii pneumonia in human immunodeficiency virus-infected adolescents and adults in the United States: reassessment of indications for chemoprophylaxis. J Infect Dis; 178:1126-32.

Kidd .S.E., Y. Chow, S. Mak, et al., (2007): "Characterization of environmental sources of the human and animal pathogen Cryptococcus gattii in British Columbia, Canada, and the Pacific Northwest of the United States," Applied and Environmental Microbiology, vol. 73, no. 5, pp. 1433-1443.

Klotz S. A., Drutz D., Zajic J. E. (1985): Factors governing adherence of Candida species to plastic surfaces. Infect. Immun. 50:97-101.

Kondo H, Taguchi M, Abe N, et al.,( 1993) : Pathological changes in epidemic porcine Pneumocystis carinii pneumonia. J CompPathol 108:261-268.

Kwon-Chung, K.J., Sorrell, T.C., Dromer, F., Fung, E., Levitz, S.M. (2000): Cryptococcosis: clinical and biological aspects. Med.Mycol. 38 (Suppl. 1), 205-213.

Lehmann, P.F., (1985): Immunology of fungal infections in animals. Vet. Immunol. Immunopathol. 10, 33-69. 
Lenard, Z.M., Lester, N.V., O’Hara, A.J., Hopper, B.J., Lester, G.D.,(2007) :Disseminated cryptococcosis including osteomyelitis in a horse. Aust. Vet. J. 85, 51-55.

McCarthy, K. (2006): High mortality rates due to cryptococcal infection in South African antiretroviral-naïve populations can be prevented. Available from: http:/www.aidsmap.com/en/news/ Accessed date: 2008 March 3.Update.26: 322-330.

McCullough MJ, Savage NW (2005): Oral candidosis and the therapeutic use of antifungal agents in dentistry. Aust Dent J. 50(Suppl 2): S36-39.

N. Jain, L. Li, D. C. McFadden, et al.,(2006) : "Phenotypic switching in a Cryptococcus neoformans variety gattii strain is associated with changes in virulence and promotes dissemination to the central nervous system," Infection and Immunity, vol. 74, no. 2, pp. 896- 903.

Nelson, P. E., M. C. Dignani, and E. J. Anaissie (1994): Taxonomy, biology, and clinical aspects of Fusarium species. Clin. Microbiol. Rev. 7:479-504.

Nelson, P. E., M. C. Dignani, and E. J. Anaissie. (1994): Taxonomy, biology, and clinical aspects of Fusarium species. Clin. Microbiol. Rev. 7:479-504.

Neville BW, Damm DD, Allen CM, Bouquot JE (2002): Fungal and protozoal diseases. Oral \& Maxillofacial Pathology. 2nd ed. Philadelphia: Saunders; p. 189-197.

Ninet B, Jan I, Bontems O, et al (2005): Molecular identification of Fusarium species in onychomycoses. Dermatology; 210:21.

Nucci E, M., and. Anaissie. (2002): Cutaneous infection by Fusarium species in healthy and immunocompromised hosts: implications for diagnosis and management. Clin. Infect. Dis. 35:909-920.

Nucci M, Anaissie E (2002): Cutaneous infection by Fusarium species in healthy and immunocompromised hosts: implications for diagnosis and management. Clin Infect Dis; 35:909.

Nucci M, Anaissie E (2007): Fusarium infections in immunocompromised patients. Clin Microbiol Rev; 20:695.

Nucci M, Anaissie E (2007): Fusarium infections in immunocompromised patients. Clin Microbiol Rev; 20:69504.

Nucci M, Marr KA, Queiroz-Telles F, Martins CA, Trabasso P, Costa S, et al (2004): Fusarium infection in hematopoietic stem cell transplant recipients. Clin Infect Dis; 38:1237-42.

Nucci, M., E. J. Anaissie, F. Queiroz-Telles, C. A. Martins, P. Trabasso, C. Solza, C. Mangini, B. P. Simoes, A. L. Colombo, J. Vaz, C. E. Levy, S. Costa, V. A. Moreira, J. S. Oliveira, N. Paraguay, G. Duboc, J. C. Voltarelli, A. Maiolino, R. Pasquini, and C. A. Souza (2003): Outcome predictors of 84 patients with hematologic malignancies and Fusarium infection. Cancer 98:315-319.

Nucci, M., K. A. Marr, F. Queiroz-Telles, C. A. Martins, P. Trabasso, S.Costa, J. C. Voltarelli, A. L. Colombo, A. Imhof, R. Pasquini, A. Maiolino, Aspergillus fumigatus mutants that do not produce the ribotoxin restrictocin. Mol. Microbiol.Quintessence Int.; 33: 521-532.

Odds F. C. (1988): Chronic mucocutaneous candidiosis. In Candida and candidosis. (University Park Press, Baltimore, $M d$ ), $p p$ 104-110.

Oren I, Haddad N, Finkelstein R, Row JM (2001): Invasive pulmonary aspergillosis in neutropenic patients during hospital construction: before and after chemo-prophylaxis and institution of HEPA filters. Am J Hematol; 66:257-262.

Paillaud E, Merlier I, Dupeyron C, Scherman E, Poupon J, Bories PN (2004): Oral candidasis and nutritional deficiencies in elderly hospitalized patients. Br J Nutr; 92: 861-867.

Patterson TF, Kirkpatrick WR, White M, et al (2000): Invasive aspergillosis: disease spectrum, treatment practices, and outcomes. I3 Aspergillus Study Group. Medicine; 79:

Phair J, Munoz A, Saah A, Detels R, et al, and the Multicenter AIDS Cohort Study Group(1990). The risk of Pneumocystis carinii pneumonia among men infected with HIV-1. N. N Engl J Med; 322: 61-5.

Ricketti AJ, Greenberger PA, Pruzansky JJ, et al., (1983): Hyper reactivity of mediator releasing cells from patients with allergic bronchopulmonary aspergillosis as evidence by basophil histamine release.J Allergy Clin Immunol 72: 386.

Roblot F, Godet C, Le Moal G, Garo B, Faouzi Souala M, Dary M, et al (2002): Analysis of underlying diseases and prognosis factors associated with Pneumocystis carinii pneumonia in immunocompromised HIVnegative patients. Eur J Clin Microbiol Infect Dis; 21:523-31.

Romani L., Puccetti P., Bistoni F. (1996): Biological role of Th cell subsets in candidiasis. in Th1 and Th2 cells in health and diseases. ed Romagnani S. (Karger, Farmington, Conn), pp 114-137.

Romani, L. (2004): Immunity to fungal infections. Nat. Rev. Immunol. 4, 1-23.

Ross I. K., DeBernardis F., Emerson G. W., Cassone A., Sullivan P. A.(1990):The secreted aspartate proteinase of Candida albicans: physiology of secretion and virulence of a proteinase-deficient mutant. J. Gen. Microbiol. 136:687-694.

Sherman RG, Prusinski L, Ravenel MC, Joralmon RA (2002): Oral candidosis. Br. J. Haematol. 129:569-582.

Shoham, S., and S. M. Levitz.(2005) :The immune response to fungal infections. Microbiol. Infect. Dis. 19, 671- 
678.

Smith, J. M., J. E. Davies, and D. W. Holden. (1993): Construction and pathogenicity of

Soll D. R. (1988): High frequency switching in Candida albicans and its relations to vaginal candidiasis. Am. J. Obstet. Gynecol. 158:997-1001.

Soll D. R. (1992): High-frequency switching in Candida albicans. Clin. Microbiol. Rev. 5:183-203.

Sorrell T.C. (2001): “Cryptococcus neoformans variety gattii," Medical Mycology, vol. 39, no. 2, pp. 155-168.

Souza .C.A., and Anaissie .E.(2004) : Fusarium infection in hematopoietic stem cell transplant recipients. Clin. Infect. Dis. 38:1237-1242.

Steele, C., Shellito, J.D., Kolls, J.K., (2005): Immunity against the opportunistic fungal pathogen Pneumocystis. Med. Mycol. 43, 1-19.

Stringer JR, Beard CB, Miller RF, Wakefield AE (2002): A New Name (Pneumocystis jiroveci) for Pneumocystis from Humans. Emerg Infect Dis; 8(9):891-896.

Sweeney MP, Bagg J, Fell GS, Yip B (1994): The relationship between micronutrient depletion and oral health in geriatrics. J Oral Pathol Med.; 23: 168-171.

Tanaka S, Kaji Y, Taniyama H, et al., (1994): Pneumocystis carinii pneumonia in a thoroughbred foal. J Vet Med Sci 56:135-137.

The Center for Food security and Public Health (2013): Cryptococcosis Torulosis, European Blastomycosis, Busse-Buschke's Disease, College of Veterinary Medicine, Iowa state University, Last Updated: February 2013.

The Pneumocystis Workshop (1994): Revised nomenclature for Pneumocystis carinii J Eukaryot Microbiol; 41(5):121S-122S.

Torres HA, Kontoyiannis DP (2011): Hyalohyphomycoses (Hyaline Moulds). In: Essentials of Clinical Mycology, Second edition, Kauffman C, Pappas PG, Sobel JD (Eds), Springer, New York. p.281.

Traynor, T.R., Huffnagle, G.B., (2001): Role of chemokines in fungal infections. Med. Mycol. 39, 41-50.

Traynor, T.R., Huffnagle, G.B.,( 2001) : Role of chemokines in fungal infections. Med. Mycol. 39, 41-50.

Uicker, W.C., Doyle, H.A., McCracken, J.P., Langlois, M., Buchanan, K.L. (2005): Cytokine and chemokine expression in the central nervous system associated with protective cell-mediated immunity against Cryptococcus neoformans. Med. Mycol. 43, 27-38.

Van Burik JA, Magee PT (2001): Aspects of fungal pathogenesis in humans.

Waring, P. (1990): DNA fragmentation induced in macrophages by gliotoxin does not require protein synthesis and is preceded by raised inositol triphosphate levels. J. Biol. Chem.

Washburn RG, DeHart DJ, Agwa DE, and Bryant-Varela BJ, Julian NC (1990): Aspergillus fumigatus complement inhibitor: production, characterization, and purification by hydrophobic interaction and thin-layer chromatography. Infect Immun 58: 3508-3515.

Wickern, G. M. (1993): Fusarium allergic fungal sinusitis. J. Allergy Clin. Immunol. 92:624-625.

Williams DW, Kuriyama T, Silva S, Malic S, Lewis MA (2011) : Candida biofilms and oral candidosis: treatment and prevention. Periodontol; 55: 250-265.

Williams et al.; Williams WP, Windham GL, Buckley PM, Perkins JM (2004): Southwestern corn borer damage and aflatoxin accumulation in conventional and transgenic corn hybrids next term. Agronomy Journal. ; NS (NS):

Winn, R. M., C. Gil-Lamaignere, E. Roilides, M. Simitsopoulou, C. A. Lyman, A. Maloukou, and T. J. Walsh (2005): Effects of interleukin-15 on antifungal responses of human polymorphonuclear leukocytes against Fusarium spp. and Scedosporium spp. Cytokine 31:1-8. 